$\xi=-1$

\title{
Chassis Structural Design of Track Racing One Manned Formula Car
}

\author{
J.W. Lim ${ }^{1}$, S.Sivaguru ${ }^{1 *}$ \\ ${ }^{1}$ School of Engineering and Physical Sciences, Heriot-Watt University Malaysia \\ *Corresponding author E-mail s.sivaguru@hw.ac.uk:
}

\begin{abstract}
The current work contains the design and optimisation of a spaceframe chassis for a track racing one manned formula car able to participate in the Formula Society of Automotive Engineers (Formula SAE) 2017/2018. Materials, profile cross section types were sele cted by considering the theories of elastic failure. The structural strength of the chassis was determined by Finite Element Analysis using ABAQUS software by determining the stress distribution during static and dynamic loading in addition to exposing the modal frequencies. Beam elements were used in the finite element model as it provides accurate modelling of small deflection bending responses. A simple baseline chassis design was developed that adheres to the Formula SAE 2017/2018 rules. Optimisations were made in terms of the configuration and material utilisation of the chassis members were done to prevent yielding during the static loading of car components and dynamic loading during acceleration and cornering. Furthermore, the same method of optimisation was used in prevention of the coincidence of natural frequency with the frequency of the engine.
\end{abstract}

Keywords: Chassis; Dynamic Analysis; Finite Element Analysis; Formula Car; Optimisation

\section{Introduction}

The main objective of this report is to design, simulate and build an internal combustion engine Formula SAE (Society of Automotive Engineer) race car to compete against other universities from around the world. In this report, the design will focus upon the design of the chassis to with considerations to safety, aerodynamics, weight, and structural strength. Finite Element Analysis using ABAQUS software was done to optimize the following characteristics of the chassis design.

\subsection{Formula SAE Background and Rules}

Formula SAE is an international engineering design competition that empowers university students to design, develop and build a formula-style, open-wheel, single-seated race car. The main objective to build the race car is to race against other universities from around the world.

The concept behind the Formula SAE competition is a student design team is to design, manufacture, and market a nonprofessional, weekend autocross race vehicle. So, the student design team must design, build and test a prototype based on a series of rules that focuses on the on-track safety to the driver, fuel efficiency, dynamic endurance fuel efficiency and cost.

\subsection{Objective}

The main objective of this paper is to design and optimize a spaceframe one manned formula-style car chassis design for future Formula SAE competitions based on structural and dynamic considerations using commercial simulation package. According to Singh,RP, the balance between the weight of chassis and torsional rigidity is important in order to provide optimal traction as was obtained in his chassis design of $32 \mathrm{~kg}$ [1]. A design requirement hierarchy was developed as shown in Figure 1.

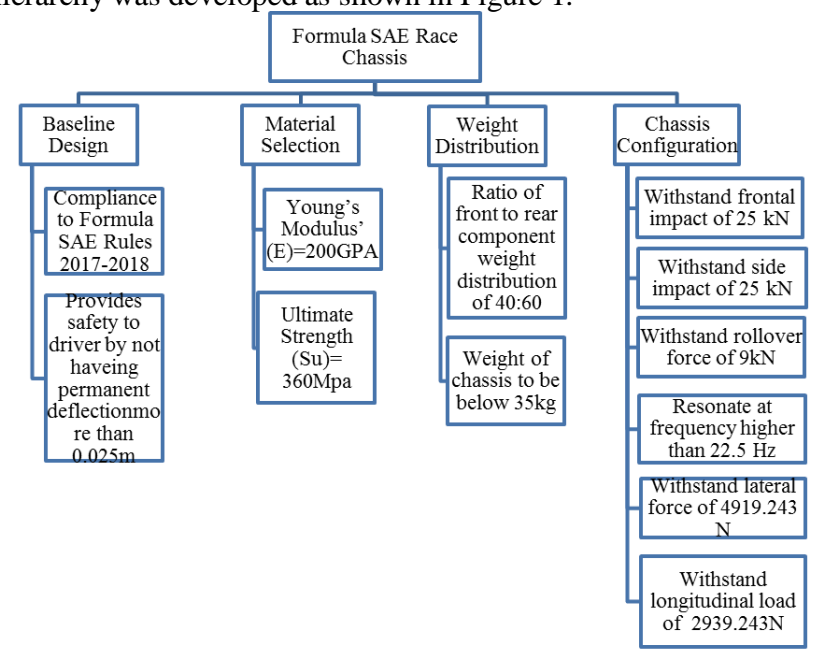

Fig. 1: Design requirement hierarchy

\section{Baseline Model}

The baseline model serves as the reference for comparison for the optimized designs in this study. A spaceframe of simple configuration of uniform profile cross section was drawn using CREO Parametric 3.0. The parts labelled Front Bulkhead Load, Main Roll Hoop, Front Roll Hoop, Shoulder Attachment, Lap Attachment and Anti-Submarine Attachment were parts designed adhering to the Formula SAE rules and regulations. These locations are featured in Figure 2. The orange highlighter points in the figure 
show the constrained locations in the $\mathrm{x}, \mathrm{y}$ and $\mathrm{z}$ axis directions. The baseline model is in fulfilment of the requirements set in the Formula SAE 2017-18 rules.

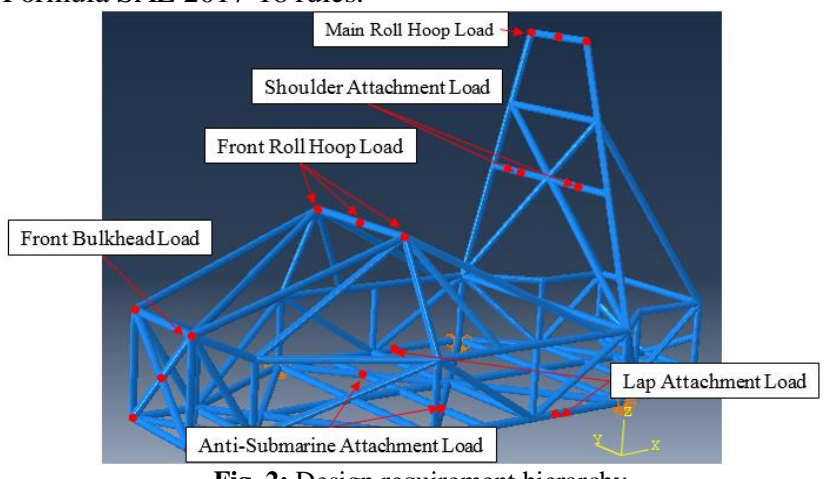

Fig. 2: Design requirement hierarchy

\section{Roll Analysis}

The Front Roll Hoop has a shorter height and more brace supports, it can easily withstand the impact due to the increased stiffness. This is opposed to the Main Roll Hoop, which is longer and only has one pair of brace members. Although the stress distributed to the Side Impact Members and the brace members, the Main Roll Hoop experienced yielding at the node of the brace members. The top of the Main Roll Hoop does not yield. Since the helmet of the driver is $50 \mathrm{~mm}$ from the top of the Main Roll Hoop, the yielding and deflection of the Main Roll Hoop can protect the driver from impact with the ground. The design provides a safety factor of 1.919 and shows less deflection than Shahade P.R's design of $58.4 \mathrm{~mm}$ [2]. Figure 3 shows the final optimized design's von Mises stress and deflection fringe plots.

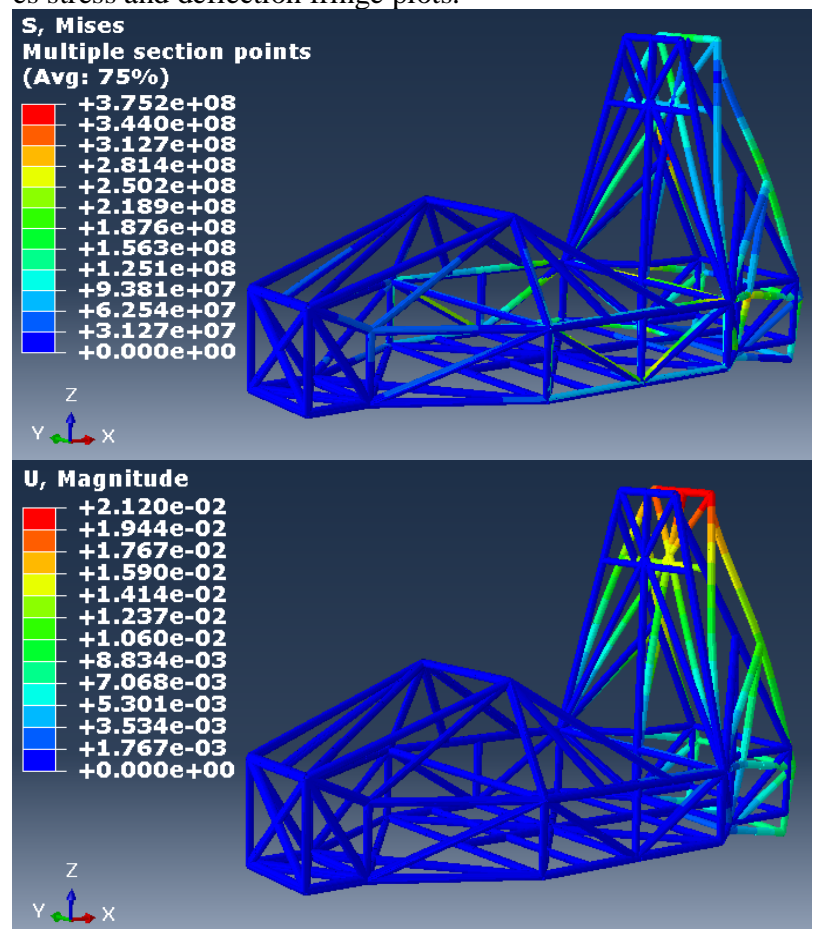

Fig. 3: Main roll hoop optimized stress and deflection fringe plot

\section{Frontal Impact Analysis}

The entire chassis was built using hollow tubes of SAE AISI 4130 steel diameter $25.4 \mathrm{~mm}$ and thickness of $0.8 \mathrm{~mm}$. From the analysis, as shown in Figure 4, it is seen that the bottom base of the chassis is susceptible to failure. There is significant deformation at the base of the cockpit. The base side impact member of the cockpit shows deflection of $35.25 \mathrm{~mm}$. This is out of the range of tolerance given by the Formula SAE rules of $25.0 \mathrm{~mm}$. However, the deflection of the base of the chassis surpasses the maximum deflection set in the Formula SAE rules. The base of the chassis shows deflection of $45.06 \mathrm{~mm}$. This is over the tolerance given by the Formula SAE rules. This is due to the Anti-Submarine Attachment point. To overcome the problem of over-deflection of the AntiSubmarine attachment point. The tubes used for this section will have increased thickness.

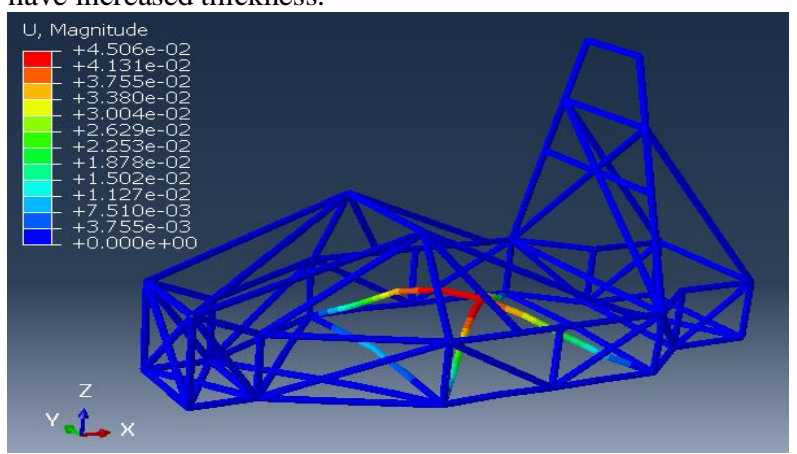

Fig. 4: Deflection of chassis due to loading requirement set in Formula SAE rules 2017-18

A thicker tube profile of radius $13.5 \mathrm{~mm}$ and thickness of $1.6 \mathrm{~mm}$ was assigned to the base of the chassis. This effectively reduced the maximum deflection to $23.75 \mathrm{~mm}$, below the stipulated maximum $25 \mathrm{~mm}$ deflection stated in the Formula SAE rules. Figure 5 shows the improved design stress and deflection fringe plots.

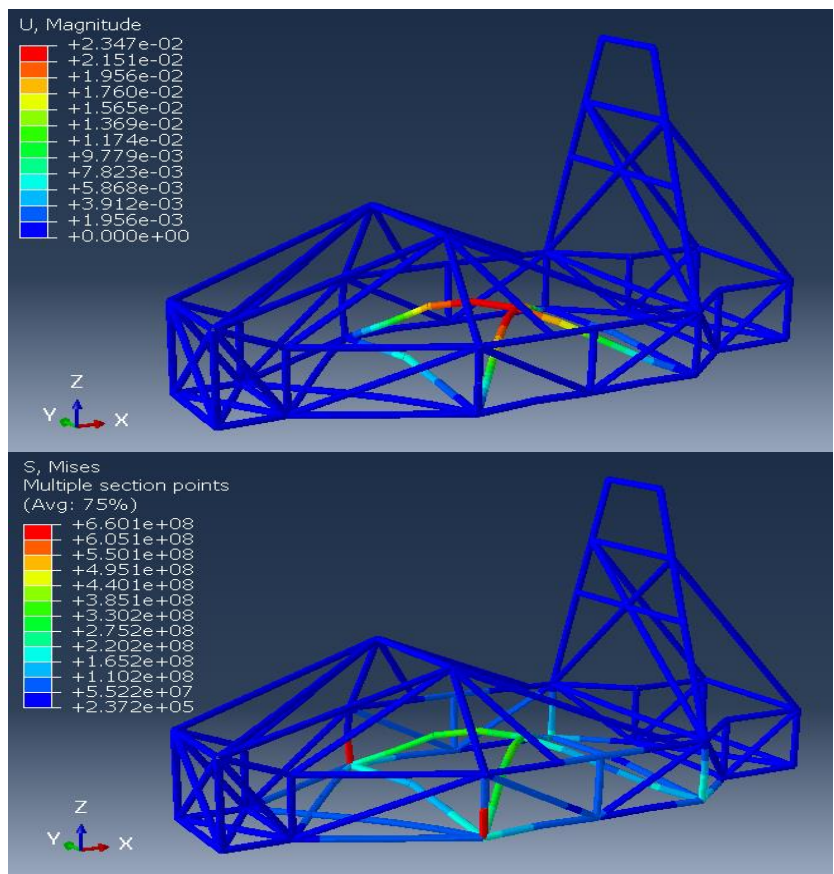

Fig. 5: Deflection of chassis due to loading requirement set in Formula SAE rules 2017-18

The shoulder attachment serves as the attachment points for the shoulder harness. The simulation was done by exerting $7 \mathrm{kN}$ at the shoulder harness attachment points. This is to simulate the event of an impact or emergency braking. Figure 6 shows the shoulder attachment load simulation for both deflection and von misses stress fringe plots. 


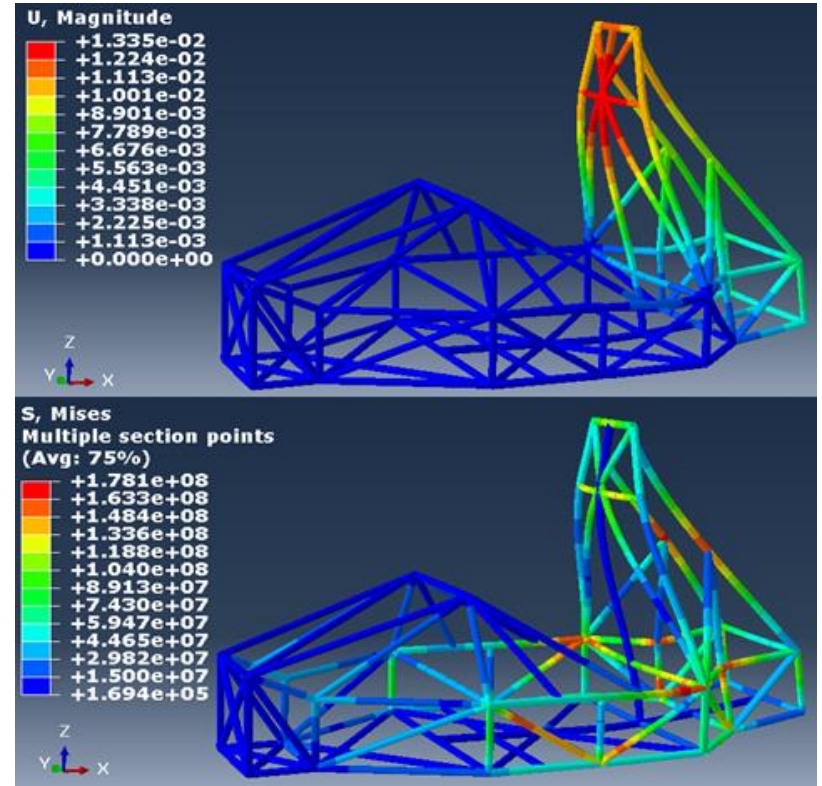

Fig. 6: Deflection of chassis due to loading requirement set in Formula SAE rules 2017-18

The shoulder attachment load is directed to the front of the chassis to simulate an event of emergency brake. Since modification was done to optimize the strength of the main roll hoop, the bracings kept deflection of the shoulder attachment at $13.35 \mathrm{~mm}$. The triangulation of the brace members at the Main Roll Hoops distributed the stress during the simulation. This results in a maximum stress distribution of $178.1 \mathrm{MPa}$ which is less than the yield strength of the chassis of $360 \mathrm{MPa}$.

The base requirement for the Front Bulkhead is to have $120 \mathrm{kN}$ of force exerted at the attachment points for the impact attenuator. Also, the deflection of the chassis must not exceed $25 \mathrm{~mm}$. An additional member was addded diagonally between the front hoop and the front bulkhead to stiffen the chassis. Figure 7 shows the optimized model's simulation fringe plot.

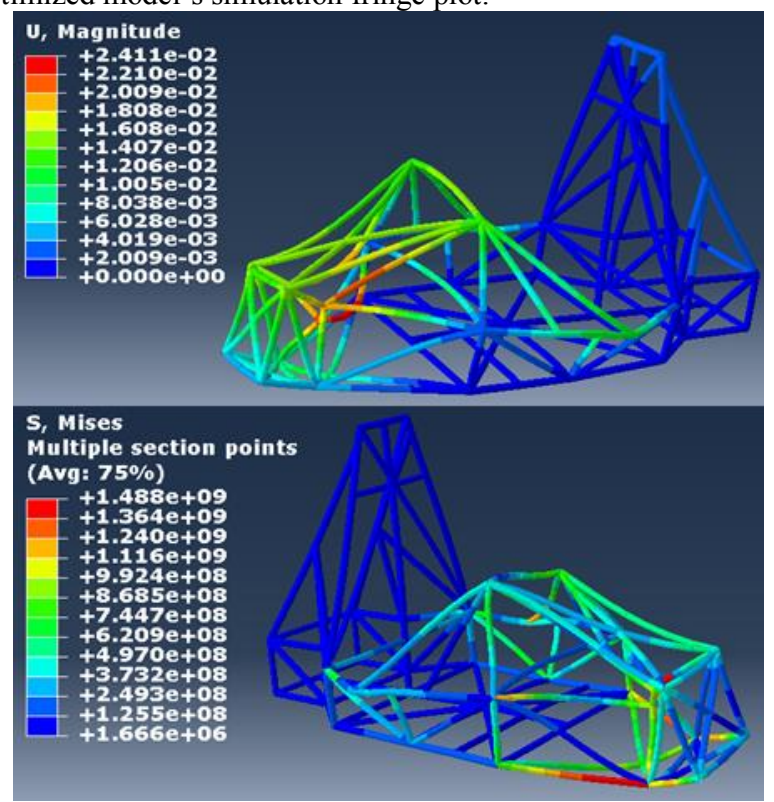

Fig. 7: Optimized model simulation fringe plots

The results show $24.11 \mathrm{~mm}$ of deflection after optimisation. However, the stress distribution shows yielding at the base brace members to the Front Bulkhead. As the analysis deals with an object colliding with the chassis at $480 \mathrm{~km} / \mathrm{hr}$ and delivering $120 \mathrm{kN}$ of impulse, this is not going to happen on the race track as the engine capacity set in Formula SAE only allowed cars to accelerate to 96 $\mathrm{m} / \mathrm{s}$.

\section{Side Impact Analysis}

An evenly distributed side impact of $7 \mathrm{kN}$ was imposed on the side impact members. $7 \mathrm{kN}$ represents the impulsive force imparted by another Formula SAE race car. This assumes the car crashing into this chassis is travelling at $151.2 \mathrm{~km} / \mathrm{hr}$ and stops abruptly upon impact with the chassis. This is an over estimate as the speed of Formula SAE race cars are impeded by the $710 \mathrm{cc}$ engine that allows for top speeds of up to $96 \mathrm{~km} / \mathrm{hr}$ in motorcycles [3].

The results show a deflection of $2.763 \mathrm{MPa}$ at the point of impact. The chassis can achieve a relatively small stress distribution due to its ability to distribute the load from the side impact to other parts of the chassis. The distribution of stress is obtained by have the members of the chassis be angled to each other and configured as triangles. This effectively increases the stiffness of the chassis.

The results are consistent with Chandan SN et al's design with $3.863 \mathrm{~mm}$ of maximum deflection of the side impact members [4]. However, the side impact load used by Chandan SN et al was $24.525 \mathrm{~N}$ [4]. This means the triangulation of the design shown in Figure 8 can withstand larger loads with smaller deflections.
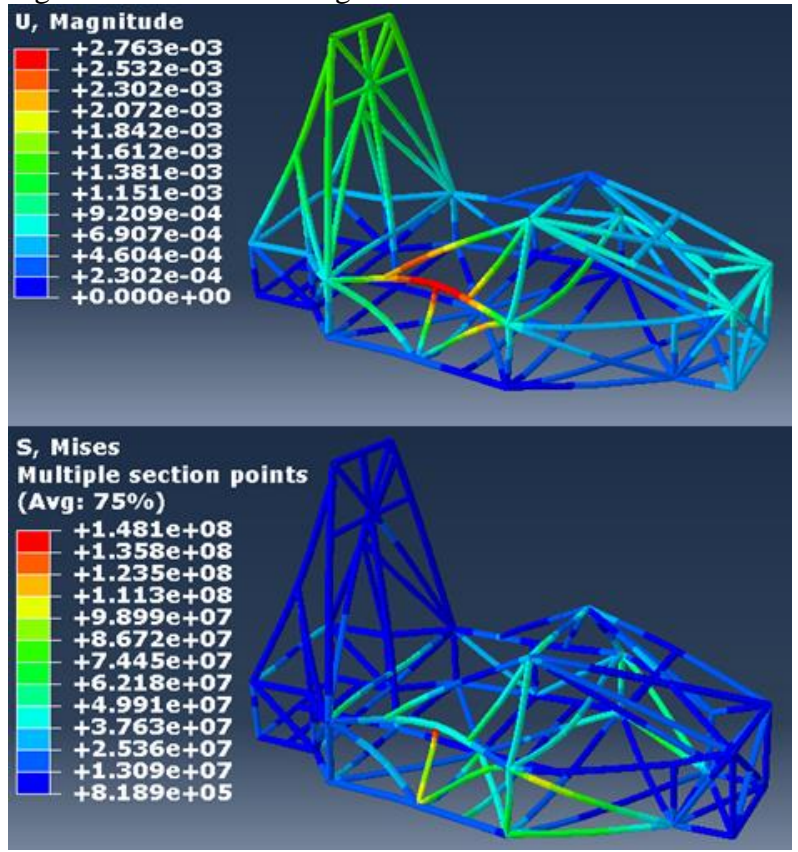

Fig. 8: Side impact simulation fringe plots

It is observed that the deflection of the Front Roll Hoops, Main Roll Hoops, Bracings, Shoulder Harness attachment points and lap attachment points. This shows that the structure of the chassis can meet the structural requirements set in the Formula SAE rules. Since the Von Mises stress of the Anti-Submarine AF Harness and Main Roll Hoops' Von Mises stress exceeds the yield strength of SAE 4130 steel, permanent deformation occurs. Since the maximum deflection to occur is $23.47 \mathrm{~mm}$, the safety of the driver is assured.

\section{Static Load Analysis}

According to Deeraj S et al., static analysis is used to determine the failure modes of a loaded model when stationary in which non-linearities due to plasticity stress stiffening, hyper elasticity, contact surfaces and creep can be ascertained [5]. However, this is beyond the scope of this paper as only the Von Mises stress is simulated.The total load each section of the chassis is distributed in its respective section. This is to simplify the application of load and to reduce the risk of under-loading the chassis. Figure 9 shows the simulation fringe plots. 


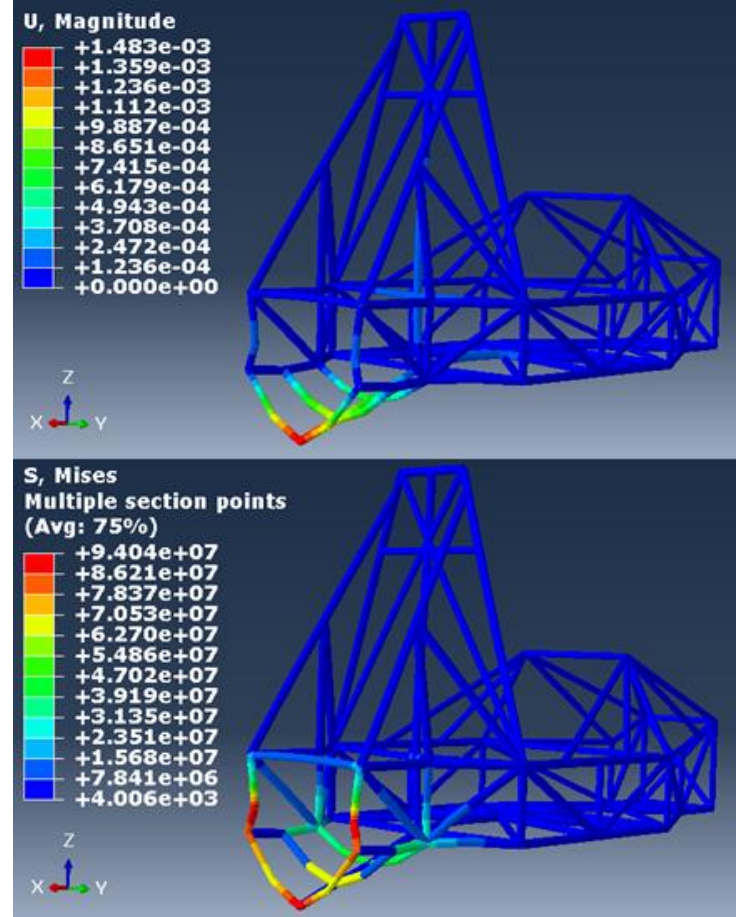

Fig. 9: Simulation fringe plots of Static weight distribution on chassis

The area most affected is the rear sub-chassis area of the chassis. The von Mises Stress at this area is $94.04 \mathrm{MPa}$, which is lower than the yield strength of the chassis which is $510 \mathrm{MPa}$. This shows a safety factor of 2.13 to the static load. Table 1 further outlines the simulation results at specific locations. Loads applied are as per SAE rule requirements.

Table 1: Tabulation of results from simulation. Loads are applied as per Formula SAE rules requirements

\begin{tabular}{|l|c|c|}
\hline Location of Applied Load & $\begin{array}{c}\text { Maximum } \\
\text { Deflection } \\
(\mathrm{mm})\end{array}$ & $\begin{array}{c}\text { Von Mises } \\
\text { Stress (MPa) }\end{array}$ \\
\hline All harness attachment points & 1.96 & 110.20 \\
\hline All harness attachment points & 23.47 & 385.10 \\
\hline Top of Front Hoop & 2.017 & 39.72 \\
\hline Top of the Main Roll Hoop & 24.21 & 476.70 \\
\hline $\begin{array}{l}\text { Attachment point between the harness } \\
\text { and the main roll hoop }\end{array}$ & 15.26 & 239.00 \\
\hline All harness attachment points & 1.96 & 110.20 \\
\hline
\end{tabular}

\section{Pitching Load Transfer}

When the chassis accelerates or decelerates, the inertial forces produced will make the car lean backwards and nosedive. Consequently, the centre of gravity will shift backwards during acceleration and shift forward during braking. This puts additional load onto the wheel attachment points of the chassis.

Longitudinal load transfer occurs when the centre of mass of the race car is shifted from the front to the back and vice versa. During acceleration, the centre of mass is shifted to the back of the chassis. This exerts additional stress on the rear wheel attachment point. For this study, the typical top speed of $9 \mathrm{~m} / \mathrm{s} 2$ is imposed onto the chassis with reference to Darthmout College. [6]

When $9 \mathrm{~m} / \mathrm{s} 2$ of acceleration occurs, the resultant load exerted on the rear wheels are $1328.967 \mathrm{~N}$. This translates to $664.484 \mathrm{~N}$ on each rear wheel attachment. A free body diagram of the chassis is shown in Figure 10.

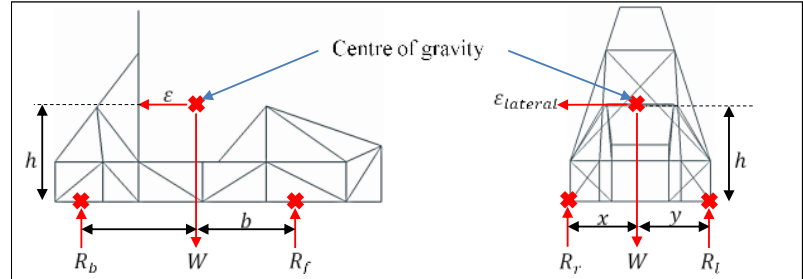

Fig. 10: Free body diagram of chassis when accelerating

Taking the sum of moment around the rear wheel gives the reaction force of the front wheel Rf.

$R_{f} \quad=\quad \frac{b}{a+b} W-\frac{h}{a+b} m \varepsilon$

The load exerted onto the rear wheels can be calculated as:

$R_{b}=\frac{W a-m c h}{a+b}$

The load exerted between the two rear-wheels were assumed to be shared equally. This means $664.484 \mathrm{~N}$ of force while be exerted at both rear wheel attachment. The acceleration of the chassis incurs bending of the chassis due to inertial forces in addition to exerting additional force at the back of the chassis. The additional downward force is located at the attachment point of the drivetrain.

The simulation results show $306.8 \mathrm{MPa}$ of maximum stress present round the base of the chassis. The analysis was done by neglecting the reaction force from the wheels. This results in a higher stress distribution as indicated in Figure 31. The analysis was done to prove that the chassis can withstand the high stress during acceleration by itself.

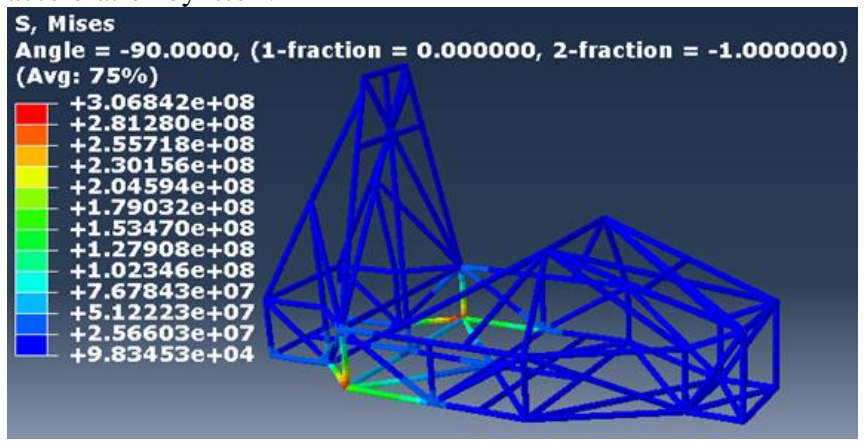

Fig. 11: Stress distribution of chassis when accelerating

According to Kudarauskas N, the general case of deceleration for a car is $8.6 \mathrm{~m} / \mathrm{s} 2$ when it is travelling at $80 \mathrm{~km} / \mathrm{hr}$ [7]. To study the effects of braking on the chassis, a deceleration of $8.6 \mathrm{~m} / \mathrm{s} 2$ was imposed on the chassis. The load used during deceleration are calculated using moment equilibrium equations as was done for acceleration based on the free body diagram shown in Figure 12.

Taking the sum of moment around the front wheel gives the reaction force at the back wheel.

$R_{b}=\frac{b}{a+b} W-\frac{h}{a+b} m \varepsilon$

The load exerted onto the rear wheels is calculated as follows:

$R_{f}=\frac{W a+m c h}{a+b}$ 


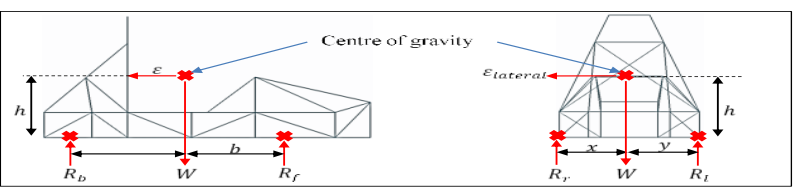

Fig. 12: Free body diagram of chassis when braking

The total load exerted on the attachment point of front axle is 2886.243 N. These loads are applied in the simulation. The boundary conditions were set at the suspension attachment point located at the base of the Front Roll Hoop. Results show 110.5 $\mathrm{MPa}$ of stress between the suspension attachment point and the axle attachment point. No yielding occurs.

\section{Lateral Load Transfer}

The chassis must withstand the stress induced during cornering at the skid pad segment of the Dynamic event. During cornering, the centre of mass is shifted sideways. This exerts additional stress on the sides of the chassis. For a car to corner without slipping, the lateral acceleration must match the calculated value of centripetal force of the curve. Where $\varepsilon$ is the lateral acceleration, $v$ is the velocity of the race car, $R$ is the radius of the curve of the path. The lateral acceleration is calculated as follows.

$$
\varepsilon_{\text {lateral }}=\frac{v^{E}}{R}
$$

By taking the sum of moment about the left wheel, yields the rear wheel reaction force:

$$
R_{Y}=\frac{m \varepsilon_{y} h}{x+y}+\frac{W}{2}
$$

The radius of the skid pad is $16.75 \mathrm{~m}$ assuming the race car is racing at the middle of the track. The velocity of the race car is $16.475 \mathrm{~m} / \mathrm{s}$ which is calculated by dividing the distance travelled per lap in the skid pad by the time set by University of New South Wales in Formula SAE IC Class skid pad segment 2017 competition (6.388 seconds). This translates to $4919.243 \mathrm{~N}$ of force to be shared by the front and rear wheels nearer to the centre of the curve of the path of the race car.

During cornering, the chassis will be subjected to a moment about the centre longitudinal axis. In this case, the race car in traversing anti-clockwise on a skid pad. This exerts a force of $2459.622 \mathrm{~N}$ on the left rear wheel and front wheel. Thus, a load of $249.622 \mathrm{~N}$ was applied at the said wheel attachment positions. This is because the axis of rotation of the chassis is assumed to be the centre of rotation of the chassis.

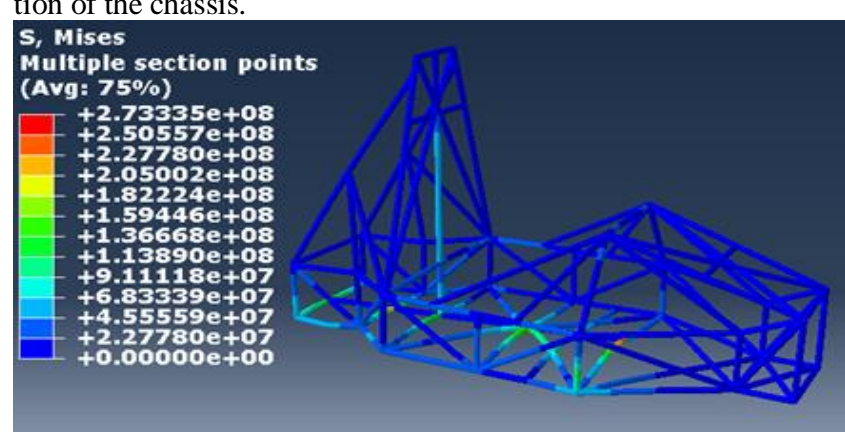

Fig. 13: lateral loading simulation of the chassis

Figure 13 shows the lateral loading simulation of the chassis. The results show 273.3 MPa of stress at the base members of the chassis. Permanent deformation and yielding shall not occur as it is well below the yield strength of 360 MPs of the chassis. An upward reaction force will be exerted at the side wheel attachment points that is equal to the downward force exerted by the lateral load transfer provided no failure occurs at the wheel attachment points. This will effectively decrease the stress distribution at the side of the chassis.

\section{Conclusion}

The SAE 4130 steel was used as the primary material to design the chassis. Standard pipe schedules sizes were used on various parts of the chassis. The final mass of the chassis is $50.328 \mathrm{~kg}$. This is approximately $15 \mathrm{~kg}$ heavier from the objective. However, the trade-off of using thicker pipe schedules provides 1.7 safety factor to extreme impacts and loads in addition to overestimated weight static load from the components and driver.

The average stress distribution across the chassis is $210.1 \mathrm{MPa}$ due to the total loading of $1948.157 \mathrm{~N}$.

Next longitudinal loading and lateral transfers $1328.967 \mathrm{~N}$ and $2886.243 \mathrm{~N}$ of load respectively. Lateral load transfer of the chassis cornering at a track of radius $16.75 \mathrm{~m}$ transfers $4919.243 \mathrm{~N}$ of load to the side.

Table 2 shows that the chassis deflects less than $25.0 \mathrm{~mm}$ as per the Formula SAE requirement. The maximum stress distribution if also well under the yield strength of $360 \mathrm{MPa}$ and is restricted to small nodes. The average stress distribution ranges from 127.9 $\mathrm{MPa}$ to $140.9 \mathrm{MPa}$. Thus methodology and optimized model of Formula SAE chassis is described in this paper.

\begin{tabular}{|c|c|}
\hline Condition & $\begin{array}{c}\text { Final } \\
\text { Design }\end{array}$ \\
\hline Maximum Deflection Rollover (m) & 0.1335 \\
\hline Maximum Deflection Frontal Impact (m) & 0.2411 \\
\hline Maximum Deflection Side Impact $(\mathrm{m})$ & 0.0027 \\
\hline Maximum Deflection Harness attachment (m) & 0.1335 \\
\hline Maximum Stress Distribution Static Loading (MPa) & 94.04 \\
\hline $\begin{array}{l}\text { Maximum Stress Distribution Longitudinal Load Transfer } \\
\text { Acceleration at } 9 \mathrm{~m} / \mathrm{s}^{2}(\mathrm{MPa})\end{array}$ & 306.842 \\
\hline $\begin{array}{l}\text { Maximum Stress Distribution Longitudinal Load Transfer } \\
\text { Braking at } 9 \mathrm{~m} / \mathrm{s}^{2}(\mathrm{MPa})\end{array}$ & 110.458 \\
\hline $\begin{array}{l}\text { Maximum Stress Distribution Lateral Loading Lateral ac- } \\
\text { celeration of } 16.025 \mathrm{~m} / \mathrm{s}^{2}(\mathrm{MPa})\end{array}$ & 273.335 \\
\hline Lowest Natural Frequency with fixed rigid engine (Hz) & 24.598 \\
\hline
\end{tabular}

Table 2: Tabulation of simulation results (deflection)

\section{References}

[1] Singh RP," Structural Performance Analysis of Formula SAE Car", Jurnal Mekanikal, Vol.1, No.31, (2010), pp.46-61, available online: https://mech.utm.my/wp-content/uploads/2017/01/5STRUCTURALPERFORMANCE-ANALYSIS-OF-FORMULA-SAE-CAR.pdf, last visit:28.05.2018

[2] Shahade PR, Kaware AK, Gulhane AM, "Structural Performance Analysis of Formula SAE Car", International Journal For Engineering Applications And Technology (IJFEAT), Vol.8, No.4, (2014), pp.32-36, available online: http://www.ijfeat.org/papers/8-Issue-4-2014.pdf, last visit: 28.05 .2018

[3] Careaga A, "Formula SAE: back in the top 10", Missouri S\&T: Experience This (2008), available online:

http://experiencethis.mst.edu/2008/05/formula_sae_back_in_the_top_10 I, last visit: 28.05 .2018

[4] Chandan SN, Sandeep GM, Vinayaka N, "Design, Analysis and Oprimization of Race Car Chassis for its Structural Performance", International Journal of Engineering Research \& Technology, Vol. 5, No. 7, (2016), pp. 361-367

[5] Dheeraj S, Sabarish R, "Analysis of Truck Chassis Frame Using FEM", Middle-East Journal of Scientific Research, Vol. 20, No. 5, (2014), pp.656-661. Available online: https://www.idosi.org/mejsr/mejsr20(5)14/20.pdf, last visit: 28.05.2018

[6] Benson KW, Fraser DA, Hatridge SL, Monaco CA, Ring RJ, Sullivan CR, Taber PC, "The Hybridization of a Formula Race Car", Vehicle Power and Propulsion, IEEE Conference (2005), pp.295-299, Available online: http://www.dartmouth.edu/ hybrid/0405/images/final-IEEEspec.pdf, last visit: 28.05 .2018

[7] Kudarauskas N, "Analysis of Emergency Braking of a Vehicle", Transport, Vol.XXII, No.3, (2007), pp.154-159, Available online: https://www.researchgate.net/publication/26541376_Analysis_of_emerg ency_braking_of_a_vehicle, last visit: 28.05.2018

[8] Fenton, J., (1996), Handbook of Vehicle Analysis. MEP, London, eBook ISBN: 9781483141640 